\title{
HIV/AIDS surveillance in Egypt: current status and future challenges
}

S. Boutros ${ }^{l}$ and J. Skordis ${ }^{7}$

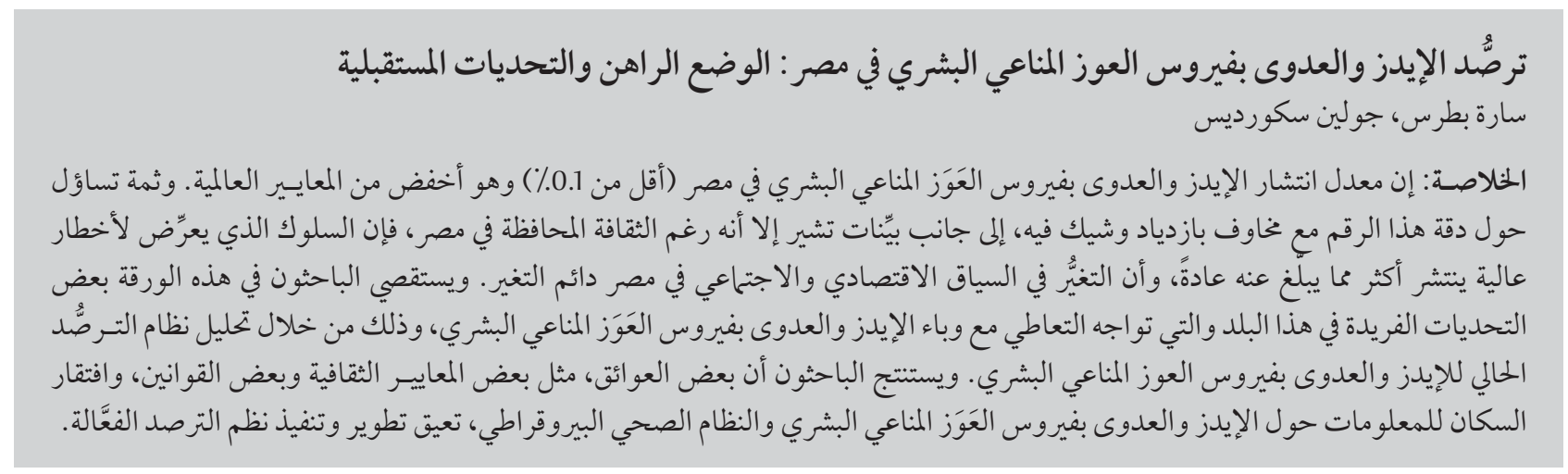

ABSTRACT By international standards, HIV/AIDS prevalence is low in Egypt $(<0.1 \%)$. However, questions about the accuracy of this figure are coupled with fears of an imminent increase in prevalence, with evidence suggesting that, despite Egypt's conservative culture, high-risk behaviour is more widespread than commonly reported and the country's changing socioeconomic context is perpetuating this trend. Through an analysis of the current HIV/AIDS surveillance system in Egypt, this paper explores some of the unique challenges this country faces in dealing with the HIV/AIDS epidemic. It concludes that constraints, such as Egypt's cultural norms and laws, the population's lack of knowledge about HIV/AIDS and the bureaucratic health system, hinder the development and implementation of effective surveillance systems.

\section{Surveillance du VIH/sida en Égypte : situation actuelle et défis à venir}

RÉSUMÉ Comparée aux normes internationales, la prévalence du VIH/sida est faible en Égypte $(<0,1 \%)$. Cependant, les interrogations sur la précision de ce chiffre sont associées à la crainte d'une augmentation imminente de la prévalence, avec des éléments qui laissent penser qu'en dépit d'une culture conservatrice en Égypte, les comportements à haut risque sont plus fréquents que communément rapporté et le contexte socio-économique qui tend à changer dans le pays accentue cette propension. Par le biais d'une analyse du système de surveillance actuel du VIH/sida en Égypte, le présent article examine certains des défis que ce pays doit relever face à l'épidémie de $\mathrm{VIH} /$ sida. II conclut que les contraintes, telles les normes culturelles et la législation égyptiennes, le manque de connaissance de la population à propos du $\mathrm{VIH} /$ sida et le système de santé bureaucratique empêchent le développement et la mise en place des systèmes de surveillance efficaces.

${ }^{7}$ Centre for International Health and Development, University College London, London, United Kingdom (Correspondence to S. Boutros: sboutros@doctors.org.uk).

Received: 17/10/07; accepted: 31/01/08 


\section{Introduction}

HIV/AIDS prevalence rates are low in Egypt at less than $0.1 \%$ in the general population $[1,2]$. However, United Nations agencies UNAIDS and UNICEF and those working within the Egyptian National AIDS Programme (NAP) fear a significant increase in this traditionally conservative society $[3,4]$, where adultery is punishable by law [3] and homosexuals are imprisoned for "habitual debauchery" [5]. The changing socioeconomic context with the ongoing economic crisis [6] has in part led to a delay in the age of marriage, which in turn has contributed to an increase in risky behaviour [1]. Indeed, in a country where sex is assumed only to happen between a husband and wife, as preached by the Muslim majority and the Coptic Christian minority [7], it is difficult to openly discuss sexuality and high-risk behaviour.

These cultural constraints, among others, are likely to challenge the way Egypt deals with its emerging HIV epidemic. More importantly, they may limit Egypt's ability to collect data on the epidemic and its determinants, despite the importance of surveillance systems in guiding monitoring and evaluating HIV-related policy and interventions, as well as in strengthening commitment, mobilizing communities and lobbying for resource allocation [8].

Through an analysis of Egypt's surveillance systems, this paper aims to give an insight into some of the unique challenges faced by this country in dealing with HIV/AIDS.

\section{Methods}

\section{Data collection and analytical framework}

To overcome the limitations created by the lack of published data on HIV/ AIDS in Egypt and improve confidence in the findings, this paper made use of the triangulation method of data collection and analysis. As explained below, secondary data from peer-reviewed papers and the grey literature were supplemented with primary data from key informant interviews.

Although the majority of available resources were grey literature and websites, it was possible to identify through extensive research a number of peerreviewed papers on the topic. Databases searched included: Medline, PubMed, Eldis, JSTOR, Web of Science, MetaLib, BioMed Central, Google Scholar and a number of relevant journals, including the Lancet, British medical journal, AIDS and Eastern Mediterranean health journal. Key search terms included "HIV" or "AIDS" in combination with "Egypt", "HIV and Middle East" as well as "HIV and Arab". Articles were then selected by scanning through the titles and abstracts for relevance to the topic. Furthermore, the reference lists of the articles extracted were checked for any additional relevant research papers.

Data from key informant interviews were used primarily to expand on, or to illustrate, discussion points raised by the literature review described above. As such, data from the key informant interviews were used only where they added to the general analysis and improved the completeness of the research, consistent with the method of triangulation [9]. The informants interviewed were selected from the government as well as from key nongovernmental organizations (NGOs) working in the field including UNAIDS and UNICEF. In total, 5 interviews were conducted. Each interview lasted approximately 1 hour and all were directly transcribed both during and immediately after the interviews. The interviews were all conducted in Arabic (the mother-tongue of the first author). They were largely unstructured; broad introductory, open questions were used to initiate the discussion. These included questions on the current state of the HIV epidemic in Egypt, on its likely future trajectory, on the kind of surveillance already in place and its findings, as well as on the obstacles encountered for surveillance and for tackling the epidemic in general. The diverse nature of the key informants prohibited any attempt to standardize the discussions around a more formal guide.

The data were later analysed using a modified grounded theory approach, a coding/editing method that extracted emerging themes from the data $[10]$. The purpose of this analysis was to group ideas and themes together to allow comparison. This highlighted commonalities as well as contradictions between the different key informants. The findings were triangulated with the secondary data to identify points of convergence and divergence and expand the total realm of understanding. The data from the interviews are therefore not quoted routinely throughout this paper. Instead, the primary data are used only where they either critically inform or contradict key issues raised by the literature review.

The analytical framework through which the data collected were examined draws on the World Health Organization (WHO) guidelines for second-generation HIV surveillance [11]. Through integration of biological and behavioural data, this surveillance system aims "to concentrate resources where they will yield information that is most useful in reducing the spread of HIV and in providing care of those affected". It is therefore also tailored to accommodate the different stages of a country's epidemic. Egypt has been consistently recognized as a low-level epidemic country $[2,3]$. However, the lack of prevalence data raises the possibility that a concentrated epidemic may already exist in high-risk groups [4]. Some evidence for this hypothesis comes from 2 recent studies, demonstrating a $6.2 \%$ and $8 \%$ infection rate in men who have sex with men (MSM) and intravenous drug users (IVDU) respectively $[4,12]$. As such, Egypt's surveillance system will be analysed in 
accordance with WHO guidelines for concentrated epidemics.

Analysis of the second-generation surveillance systems was supplemented by an overview of appropriate socioeconomic data, as these are proven indicators of HIV risk [8]. Age, sex, educational and marital status as well as migration and gender issues are crucial to our understanding of the country's epidemic [11]. At present, however, very few socioeconomic data are collected under the second-generation surveillance system. This paper argues that inclusion of these data will be a useful complement to biological and behavioural surveillance.

Figure 1 illustrates the variety of data that will be analysed to assess the epidemic, the appropriateness of the current surveillance system and the challenges faced by Egypt in dealing with the HIV epidemic.

\section{Findings}

\section{Biological surveillance}

Biological surveillance is essential for monitoring the level of HIV infection over time and analysing trends to predict possible future trajectories of the epidemic [13]. For concentrated epidemics, the WHO recommends carrying out HIV serosurveillance in at-risk sub-populations, bridging populations and the general population, as well as screening of donated blood, HIV/AIDS case reporting, surveillance of sexually transmitted infections (STIs) and other biological markers of risk [11]. But first, the relevant populations must be identified and accessed [11].

In Egypt, commercial sex workers (CSW), MSM and IVDU constitute at-risk populations [14]. Vulnerable groups include women, youth, prisoners, street children, uniformed services and refugees [14]. Bridging populations have not been officially identified, although isolated reports suggest CSW clients, the wives of MSM (73\% of MSM are married in Egypt) [4] and the sexual partners of IVDU [15] as likely groups. Biological surveillance in Egypt should thus focus firstly on MSM, CSW and IVDU and secondly on CSW clients and the sexual partners of MSM and IVDU.

\section{HIV serosurveillance}

In 2007, the NGO Family Health International (FHI) reported the results of its first round of biological and behavioural surveillance of at-risk groups [15]. Despite small sample sizes and a low number of participating women, the findings were consistent with other isolated studies $[16,17]$, i.e. a low prevalence of HIV infection ( $<1 \%)$ among all at-risk groups, except MSM, who had an infection rate of $6.2 \%$ [15]. This suggests a concentrated epidemic among MSM, although it remains to be confirmed by consistent and repeated surveillance.

Among bridging populations and the general population, little serosurveillance is being conducted. HIV

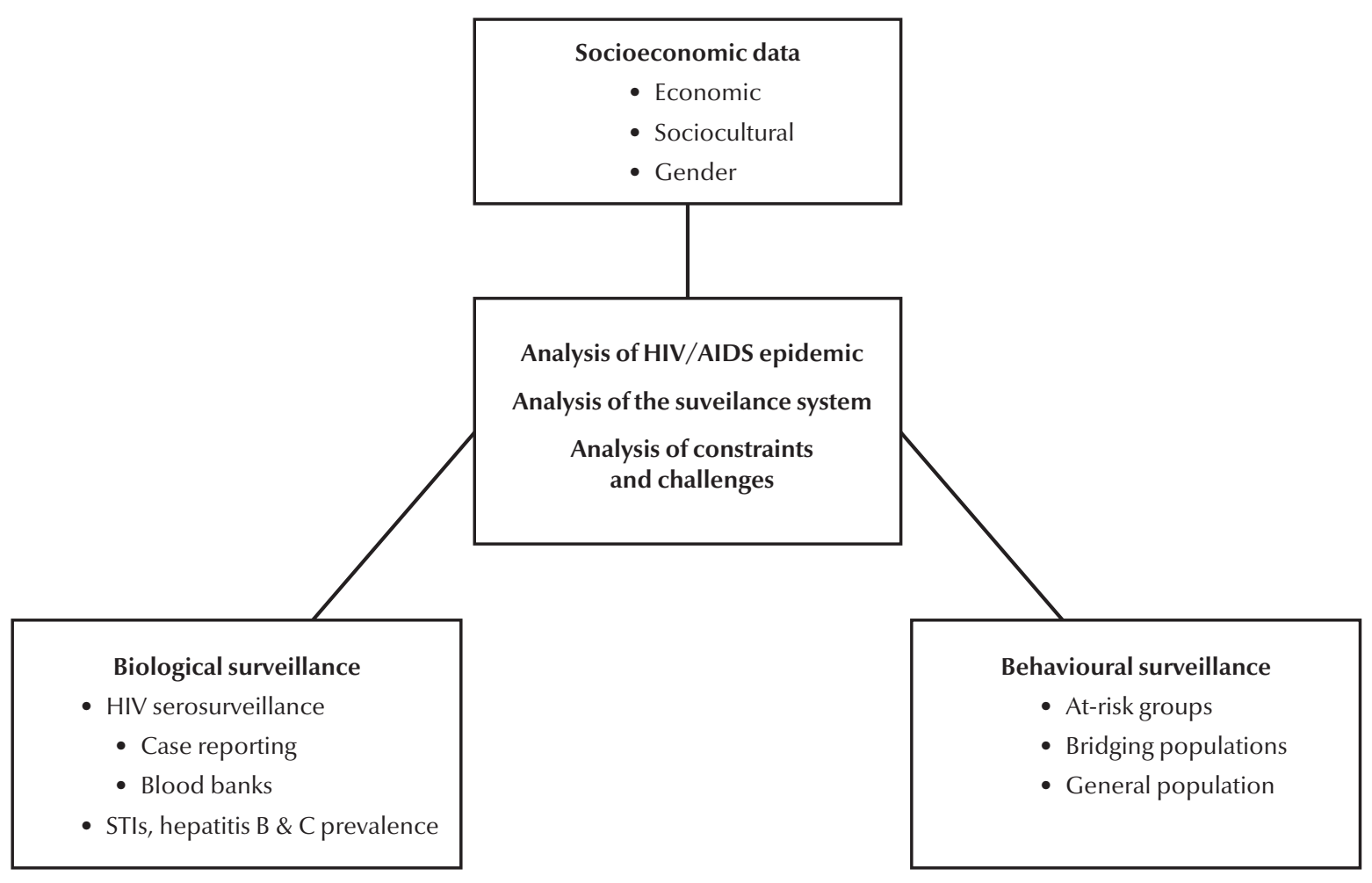

Figure 1 Framework of analysis 
screening is taking place in a number of sentinel surveillance sites including 12 tuberculosis clinics and chest hospitals, 3 sexually transmitted disease clinics and 5 antenatal clinics as well as among tourism workers and sailors presenting for work permits [3]. Although these surveillance sites do not target bridging populations and only marginally represent the general population, they constitute a positive step towards expanding Egypt's surveillance efforts.

Appropriate systematic screening of at-risk groups may be frustrated by the social stigma attached to these groups and the illegality of their behaviours [3]. Indeed, the General Penalties Laws in Egypt, as in most countries, criminalize CSW and IVDU [3]. MSM are similarly criminalized through laws regulating "inappropriate" social conduct and/or "insult to Islam" [18]. Indeed, MSM have been arrested and imprisoned on a number of occasions, despite condemnation by the NGO Amnesty International [5]. These laws combine with the highly conservative Egyptian culture to further marginalize these groups, making them difficult to access [18]. Additionally, HIV-infected people are usually seen as immoral and promiscuous [19], making surveillance more difficult to achieve. Added to this are rumours about HIV-positive people being imprisoned, as reported by one key informant, which further prevents people from using testing services.

NGOs such as FHI may have better access to at-risk groups because they are not directly under government authority, but access is particularly difficult for the NAP with its government attachment [3]. As such, despite recent improvements in Egypt's HIV surveillance effort, many continue to voice their concern that the little surveillance that is taking place is rarely representative and is leading to a systematic underestimation of the epidemic [3].

\section{HIV/AIDS case reporting}

Case detection takes place mostly in government central testing laboratories, sentinel surveillance sites, private laboratories [3] and newly opened, anonymous voluntary counselling and testing centres [20]. Positive cases are reported directly to the government's NAP, although this is not the case for private laboratories [3] whose cooperation in HIV case reporting remains unreliable according to one key informant. Current case reports, although far lower than UNAIDS estimates (5 000-13 000) [2], do point to an emerging epidemic with an increase in the number of newly reported cases [4].

Although this may be due to an increase in the number of people being tested and to improved surveillance, there is a general belief, as revealed in all the interviews, that HIV prevalence is highly underestimated and is on the increase. This may be due to weak reporting, under-utilization of voluntary counselling and testing centres, a widespread reluctance to test due to fear and stigma as discussed above [4], as well as a general lack of knowledge about the disease among health workers and the general population [21-24]. One key informant explained that most testing is currently "passive" (i.e. not related to perceived risk) with the majority of those getting tested being young males seeking "virus-free" certificates for work permits abroad [3]. Therefore, current case reporting, although indicative of an emerging epidemic, is not yet representative of the true state of the epidemic.

\section{Blood-bank surveillance}

By law, all donated blood must be screened for HIV and cases must be reported to the NAP along with the donor's identification information [3]. However, there have been a number of reported cases of infections due to blood transfusions in Egypt. In fact, 24\% of known HIV cases are attributed to the use of infected blood and/or blood products [3] and 5 outbreaks have occurred in renal dialysis units due to the reuse of syringes and dialysis equipment $[25,26]$. This number is much higher than the $5 \%$ average worldwide for such HIV infections [3]. Increased media attention prompted the Ministry of Health and Population (MOHP) to launch an infection control programme in 2003 [27]. However, remaining challenges include a lack of equipment and training, the lack of a coordinating body within the MOHP, and the highly bureaucratic and under-resourced nature of the Egyptian health care system in general $[1]$.

\section{STI surveillance and other markers of HIV risk}

In the absence of comprehensive HIV surveillance, STI surveillance is considered a useful proxy for risk factor prevalence [11]. Furthermore, ulcerative STI infection increases the risk of HIV infection and WHO now considers STI patients a high-risk group for HIV infection [11]. Hepatitis B and C also serve as proxies as they have similar modes of transmission [11].

In Egypt, national STI surveillance is virtually nonexistent although some studies were identified and are detailed in Table 1 [28-31]. These results demonstrate that STI prevalence is significantly higher than current estimates of HIV prevalence. Similarly, there is no comprehensive surveillance for hepatitis $\mathrm{B}$ and $\mathrm{C}$, although more research is being conducted on their epidemiology [3], possibly due to the longer epidemic history of hepatitis in Egypt [32] as well as the lack of stigma associated with it. As for STIs, prevalence data for hepatitis $B$ and $C$ point to the presence of high-risk behaviours that could similarly spread HIV among the general population $[33,34]$.

It is unclear whether these data have been analysed within the second-generation surveillance system. Nevertheless, this clearlyneeds to be incorporated into HIV data projections and strengthened 
as a step towards improving overall surveillance.

\section{Behavioural surveillance}

Behavioural surveillance is increasingly recognized as an essential component of any HIV/AIDS surveillance system [35]. In low-level epidemics it "can be used to identify who is at-risk of infection and which behaviours commonly put them at-risk", while in concentrated epidemics surveillance should explore the links between the at-risk and general populations [11].

Despite a lack of research into sexual and drug-taking behaviour in Egypt [3], the behaviours of at-risk groups, especially IVDU, have received some isolated study and were included in the FHI surveillance initiative mentioned earlier $[3,15]$. Between $6 \%$ and $13 \%$ of the general population use recreational drugs and about $16 \%$ to $41 \%$ of these use injected drugs [36]. About half of IVDU have ever shared or reused syringes [3]. Despite the wide availability and relatively low price of injecting equipment at pharmacies, $29 \%$ of IVDU in one study were unable to obtain a syringe from pharmacies when needed. Reasons stated include being refused purchase at pharmacies and the pharmacy being closed at the desired time [3]. As for sexual relations, of the $74 \%$ who were sexually active in one study, $15 \%$ reported having had more than 3 sexual partners in the previous month. In addition, of those who were sexually active, $50 \%$ had previously engaged in commercial sex as a provider or client and $58 \%$ of respondents had never used a condom [3].

For MSM, among whom $26 \%$ of all HIV cases occur in Egypt [14], only 2 studies could be identified, both conducted by the NAP [3]. They revealed a low rate of condom use, multiple sexual partners and receptive and total penetrative sexual acts. Regular condom use was non-existent among a sample of 80 MSM and was reported as $19 \%$ in another sample of 73 homeless MSM
[3]. Despite the wide availability of condoms in Egypt [37], reasons cited for non-use included belief that it would lower sexual satisfaction, problems with condom use and a lack of knowledge about condoms and their existence [3]. Another potential barrier to condom use may be the popular belief that condom buyers are automatically assumed to be homosexual, a highly stigmatized notion in this society [38].

Among CSW, one study of non-institutionalized female CSW described high numbers of partners and low levels of condom use [28]; $14 \%$ exhibited scars of intravenous injection (suggesting drug use) and signs of physical abuse suggesting exposure to multiple risks [28]. Studies on institutionalized female CSWs also revealed exposure to HIV risk [3]. Despite the known existence of male CSW, no behavioural studies have been carried out in this group [3].

No behavioural surveillance is currently taking place in the general population, although some data exist for vulnerable groups, particularly Egypt's youth [14]. Data from various studies show an early average age of sexual initiation, multiple sexual partners, premarital and extramarital sex (including commercial sex), injecting drug use and low levels of condom use [39]. Additionally, orfi marriages, where young people obtain a clandestine, temporary, marriage certificate allowing them to engage in sexual relations, are on the increase [7]. Although only $11 \%$ of HIV cases are currently reported among Egypt's youth, this group may become a large pool of HIV-infected persons if no action is taken, as they represent $20 \%$ of the population [3] and are still highly unaware of the disease [39-41]. Indeed "misinformation and lack of information simply increase sexual

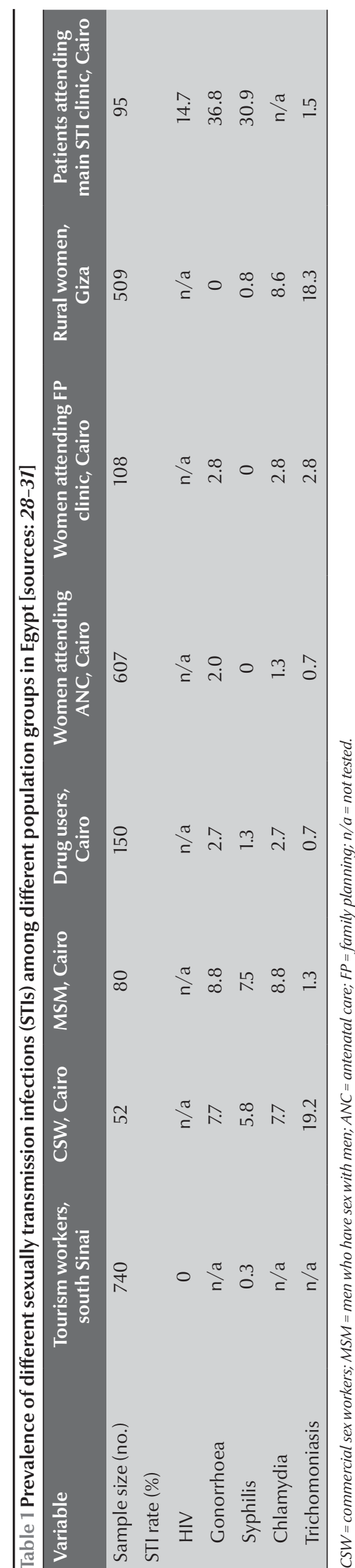


confusion and vulnerability" among young people [40].

The data above demonstrate that, apart from a number of isolated surveillance studies and the FHI surveillance initiative, there is as yet no systemic surveillance currently in place among at-risk populations. Additionally, behaviours that may link the general population to at-risk groups have not yet been explicitly studied. Possible constraints to achieving adequate surveillance may include the difficulty in accessing at-risk groups as they are illegal and stigmatized, as discussed earlier. Additionally, the conservative nature of Egyptian society may lead to reluctance to discuss sexuality and behaviours and therefore limits the ability to conduct representative behavioural surveillance. Indeed, perhaps the strongest barrier to effective behavioural surveillance is the "strong reluctance to discuss sexuality" [42]. However, in the context of Egypt, it should also be mentioned that if behavioural surveillance focused solely on at-risk groups this could have negative impacts on the public and the media as it would lead to further stigmatization of those groups as well as a decreased risk perception among the wider population, who do not engage in those risk behaviours [15]. It is therefore crucial in this context that behavioural surveillance also covers the general population. This is not yet systematically conducted.

\section{Socioeconomic surveillance}

Socioeconomic surveillance indicates the evolution of risk factors [11]. WHO advises that basic socioeconomic data such as age and sex be collected at all sentinel sites [11]. However, this paper argues that more in-depth and wider socioeconomic information is crucial to understanding and dealing with an emerging epidemic. Prevalence rates are largely determined by behaviour that is directly and indirectly affected by socioeconomic factors [13]. High unemployment, migration and illiteracy increase a country's vulnerability to HIV [11].
If these data are not integrated in the epidemiological analysis, it may leave policy-makers with the illusion that societal and economic contexts cannot impact the course of the epidemic [13]. This section will therefore give a wide overview of Egypt's socioeconomic context and will demonstrate links with existing HIV risk behaviours. This analysis will additionally serve to highlight a number of unique challenges that Egypt will have to face to deal appropriately with its emerging epidemic.

Economically, Egypt has been in crisis for a number of years with devaluation of the Egyptian pound by more than $40 \%$ between 2000 and 2001 [6]. This has led to a sharp deterioration of living standards [43]. Men have "suffered" particularly from this crisis as the financial security of the male is a prerequisite for marriage in Egyptian society [44]. Although some suggestion of an improvement has begun to emerge, the prevailing situation has resulted in a general delay in the age of marriage [1]. In a country where sex is only "allowed" in the context of marriage, this delay has increased frustration among young people. This may explain many behavioural changes, particularly the increase in premarital sex and orfi marriage discussed earlier.

Socially, conservative norms and laws prevent sexual education, as it is still believed that the theory may encourage the practice of high-risk behaviour [45]. However, Egypt may be overestimating the protective effect of its social and cultural conservatism and may therefore be giving low priority to HIV/AIDS education [46]. Indeed, political support has been hard to obtain, especially when dealing with at-risk groups, as reported by one key informant. Admitting the presence of high-risk behaviour means national leaders have to acknowledge that their citizens do not always conform to cultural and religious ideals. Although some may still believe that these conservative norms have protected Egypt from this "plague of immoral Western society" $[47,48]$, it is clear from the above analysis that this culture represents more of a challenge to, than a protection from, risk at this stage of the epidemic.

Egypt, like many countries in the Eastern Mediterranean Region, is additionally characterized by gender inequalities [42]. For example, studies show that most women are unable to request that their husbands wear a condom [49]. As a result of their limited access to information, women's knowledge of HIV is also weak [50]. Their lack of financial autonomy and overall unawareness of available resources constitute significant barriers to accessing health care [1]. However, as illustrated by data from the NAP, the female to male ratio of HIV infection stands at 1:4 [16]. Although this may be explained by the much higher rate of men testing, this ratio may also result from the particularly strong cultural prohibitions against extramarital sex applied to women. There are few data on the socioeconomic reasons underlying the lower prevalence of HIV among Egyptian women. Without these data, changes in women's positions in society and the resultant changes in behaviour cannot be appropriately monitored.

The above data have provided some insight into the complex constraints Egypt faces in dealing with its HIV epidemic. It is therefore paramount that such data be collected and analysed as an integral part of surveillance systems to both understand and limit the continuing spread of the epidemic.

\section{Discussion}

Egypt's HIV epidemic has remained low by international standards. However, as discussed here, the country risks developing a much larger epidemic. Consistently low case detection and the relative lack of behavioural surveillance may provide a false sense of invulnerability [46]. This is reinforced by an 
over-confidence in the adherence to conservative social cultural norms that prohibit sex outside marriage [46]. This could result in HIV remaining a low government priority.

That said, Egypt has a window of opportunity to stop HIV becoming a generalized epidemic. However, this can only be achieved if appropriate and timely surveillance systems are put in place. As illustrated above, a significant number of gaps were found in the current surveillance system, despite efforts by the NAP and other national and international organizations. Gaps include a lack of biological surveillance among at-risk groups, weak surveillance among women, failure to systematically and universally apply the regulations on infection control and blood-bank safety, a lack of comprehensive data on STIs, a lack of systematic and representative behavioural surveillance (especially for the general population), and a failure to integrate socioeconomic data into the surveillance system.

Four key challenges explain many of these gaps in Egypt's surveillance system. First, at-risk groups are difficult to access due to their social marginalization. MSM are arguably the most affected by this problem. Secondly, a severe lack of knowledge among health workers and the general population makes it less likely that people will seek a potential HIV diagnosis. Thirdly, the conservative nature of Egyptian society, including a general reluctance to discuss sexuality, limits the ability to conduct representative behavioural surveillance. Finally, structural factors within the NAP itself and the wider health system, ranging from understaffing, bureaucracy, limited budget allocation and fragmentation of efforts, may be constraining surveillance efforts. Further research and practical strategies are urgently needed to overcome these challenges so that appropriate surveillance can ensure a timely and appropriate response to this emerging epidemic.

\section{Acknowledgements}

We would like to thank all the key informants from UNICEF Cairo, UNAIDS Cairo and the Egyptian National AIDS Programme for their time and dedication. We would also like to thank Nabil and Sue Raphael, as well as Nadia Taher for their invaluable comments and suggestions for the final draft of this paper. Finally, we would like to thank the reviewers for their very useful input. Any remaining omissions or errors are, of course, our own.

\section{References}

1. Abdel-Rasik M. Analysis of public policy on HIV/AIDS. Cairo, Ministry of Health and Population and UNICEF, 2005.

2. Country and regional responses to AIDS: Egypt. Cairo, Joint United Nations Programme on HIV/AIDS, 2007 (http://www. unaids.org/en/CountryResponses/Countries/egypt.asp, accessed 11 August 2009).

3. El-Sayed N, Aon M, Mortagy I. Assessment of the HIV/AIDS situation and response in Egypt. Cairo, National AIDS Programme, Ministry of Health and Population and the Expanded Theme Group on HIV/AIDS, 2004.

4. Aon M. HIV situation and response in Egypt. Cairo, Joint United Nations Programme on HIV/AIDS, 2007.

5. Egypt: private internet conversation used as evidence. The Wire, 2003, April, Vol. 33, No.3. Amnesty International [online document] (http://www.amnesty.org/en/library/ asset/NWS21/003/2003/en/780c1825-d710-11dd-b0cc1f0860013475/nws210032003en.html, accessed 11 August 2009)

6. Raphaeli N. Economic crisis in Egypt. Middle East Media Research Institute, 2002 (Economic Studies No. 20) [online article] (http://memri.org/bin/articles.cgi?Page=subjects\&Area= economic\&ID=EA2002, accessed 11 August 2009).

7. DeJong J, El-Khoury G. Reproductive health of Arab young people. British medical journal, 2006, 333:849-51.

8. Rehle T et al. Second-generation surveillance: better data for decision-making. Bulletin of the World Health Organization, 2004, 82(Suppl. 2):121-7.

9. Adami MF, Kiger A. The use of triangulation for completeness purposes. Nurse researcher, 2005, 12(4):19-29.
10. Miller WL, Crabtree BF. Doing qualitative research, 2nd ed. Thousand Oaks, California, Sage, 1999.

11. UNAIDS/WHO Working Group on Global HIV/AIDS and STI Surveillance. Guidelines for second generation HIV surveillance. Geneva, Joint United Nations Programme on HIV/AIDS, 2000.

12. HIV/AIDS Profile: Egypt. Washington DC, United States Bureau of the Census, Population Division, 2000.

13. Diaz T et al. New strategies for HIV surveillance in resourceconstrained settings: an overview. AIDS, 2005, 19 (Suppl. 2):1-8.

14. Global Fund proposal form: sixth call for proposals. Cairo, Egyptian National Country Coordinating Mechanism to Fight HIV/ AIDS, TB and Malaria, 2006.

15. HIV/AIDS biological behavioural surveillance survey summary report. Cairo, Ministry of Health and Population, Family Health International and Joint United Nations Programme on HIV/ AIDS, 2006.

16. AIDS/HIV surveillance report for the period 1/4/2006 to 30/6/2006. Cairo, National AIDS Program, 2006.

17. Watts DM et al. Prevalence of HIV infection and AIDS in Egypt over four years of surveillance (1986-1990). Journal of tropical medicine and hygiene, 1993, 96:113-7.

18. Srikameswaran A. Egypt's fearful gays shy from HIVtesting. International reporting project, Paul H. Nitze School of Advanced International Studies of the Johns Hopkins University [online article] (http://www.internationalreportingproject.org/stories/detail/575/, accessed 11 August 2009). 
19. Shahine G. Facing up to AIDS. Al-Ahram weekly, 2004, 10 March 2004, 679 (Issue No. 4) (http://weekly.ahram.org.eg/ print/2004/680/eg2.htm, accessed 11 August 2009).

20. Ingram S. New HIV/AIDS counselling and testing centres open in Egypt. United Nations Children's Fund [online article], 2005 (http://www.unicef.org/aids/egypt_28921.html, accessed 11 August 2009).

21. Megeid AA et al. Knowledge and attitudes about reproductive health and HIV/AIDS among family planning clients. Eastern Mediterranean health journal, 1996, 2(Suppl. 3):459-69.

22. Faris R, Shouman A. Study of the knowledge and attitude of Egyptian health care workers towards occupational HIV infection. Journal of the Egyptian Public Health Association, 1994, 69(Suppl. 1/2):115-28.

23. Sallam SA et al. Continuing medical education needs regarding AIDS among Egyptian physicians in Alexandria, Egypt and in the Asir region, Saudi Arabia. AIDS care, 1995, 7(Suppl. 1):49.

24. Sallam SA et al. HIV/AIDS knowledge, perception, and risk behaviour among patients suspected to have STDs in Alexandria, Egypt. American journal of epidemiology, 2001, 153(Suppl. 11):190

25. Hassan NF et al. HIV infection in renal dialysis patients in Egypt. AIDS, 1994, 8(Suppl. 6):853.

26. El Sayed NM et al. Epidemic transmission of HIV in renal dialysis centres in Egypt. Journal of infectious diseases, 2000, 181:91-7.

27. Talaat $\mathrm{M}$ et al. Evolution of infection control in Egypt: achievements and challenges. American journal of infection control, 2006, 34(Suppl. 4):193-200.

28. AbdelSattar A et al. Evaluation of selected reproductive health infections in various Egyptian population groups in Greater Cairo. Cairo, Ministry of Health and Population, IMPACT/Family Health International and Joint United Nations Programme on HIV/AIDS, 2002

29. Ali F et al. Prevalence of certain sexually transmitted diseases in Egypt. Journal of the Egyptian Public Health Association, 1996, 71(Suppl. 5/6):553-75.

30. El-Sayed NM et al. Seroprevalence survey of Egyptian tourism workers for HBV, HCV, HIV and Treponema pallidum infections: association of HCV infections with specific regions of Egypt. American journal of tropical medicine and hygiene, 1996 , 55(Suppl. 2):179-84

31. Khattab H, Younis N, Zurrayk. Women, reproduction and health in rural Egypt. The Giza study. Cairo, American University in Cairo Press, 1990.

32. Mohamed MK et al. Viral hepatitis C infection among Egyptians, the magnitude of the problem: epidemiological and laboratory approach. Journal of the Egyptian Public Health Association, 1996, 71(1/2):79-111.

33. El Ghazzawi $\mathrm{E}$ et al. Intravenous drug addiction: a high risk group for infection with human immunodeficiency virus, hepatitis viruses, cytomegalovirus and bacterial infections in Alexandria, Egypt. Journal of the Egyptian Public Health Association, 1995, 70(1/2):127-50.
34. Quinti I et al. Seroprevalence of HIV and HCV infections in Alexandria, Egypt. Zentralblatt bacteriology, 1995, 283(2):239-44.

35. Brown T. Behavioural surveillance: current perspectives, and its role in catalyzing action. Journal of acquired immunodeficiency syndrome, 2003, 32(Suppl. 1):S12-7.

36. UNOCD. Rapid assessment of trends and patterns of drug abuse in Egypt. Cairo, United Nations Office on Drugs and Crime and Ministry of Health, 2001.

37. Kandela P. Arab nations: attitudes to AIDS. Lancet, 1993, 341:884-5.

38. Srikameswaran A. AIDS fight hurt by Egyptian men's shunning of condoms. International reporting project, Paul H. Nitze School of Advanced International Studies of the Johns Hopkins University [online article] (http://www.internationalreportingproject.org/stories/detail/577/, accessed 11 August 2009).

39. Aon M. Young people and HIV/AIDS. A qualitative study in Cairo and Qena. Cairo, Joint United Nations Programme on HIV/ AIDS, 2004.

40. Farghaly AG, Kamel MM. The study of the opinion and level of knowledge about AIDS problem among secondary school students and teachers in Alexandria. Journal of the Egyptian Public Health Association, 1991, 66(Suppl. 1/2):209-25.

41. Ginedy M, El-Sayed N, Darwish A. Knowledge and attitudes of teenage students in relation to sexual issues. Eastern Mediterranean health journal, 1998, 4(Suppl. 1):76-80.

42. Obermeyer CM. HIV in the Middle East. British medical journal, 2006, 333:851-4.

43. Country report: Egypt. Egypt at a glance 2007-08. London, Economist Intelligence Unit, 2006.

44. John A. The socio-cultural context of population programs. Bochum, Germany, Institute of Development Research and Development Policy, 1997 (http://www.ruhr-uni-bochum.de/ iee/publ/mat/pdf/mat_161.pdf, accessed 11 August 2009).

45. Luyendenijk J. “Egypt doesn't have AIDS, so it doesn't need AIDS education". Sexual health exchange, 2001, 2:10-1.

46. Jenkins C. Overview of the HIV/AIDS situation in the MENA region. Washington DC, World Bank, 2001.

47. Lenton C. Will Egypt escape the AIDS epidemic? Lancet, 1997, 349:1005

48. Soliman S. Egypt's fundamentalists say condoms immoral. AIDS analysis Africa, 1995, 5(Suppl. 3):14-5.

49. Afifi AA. Factors influencing participation for prevention of HIV/STDs in an urban community in Cairo-Egypt. In: Proceedings of the International Conference on AIDS, 7-12 July, 2002, 14 (abstract number F12160) (http://gateway.nlm.nih.gov/ MeetingAbstracts/ma?f=102254008.html, accessed 11 August 2009).

50. Sallam SA et al. Reproductive tract infections among married women in Upper Egypt. Eastern Mediterranean health journal, 2001, 7(Suppl. 1/2):139-46. 